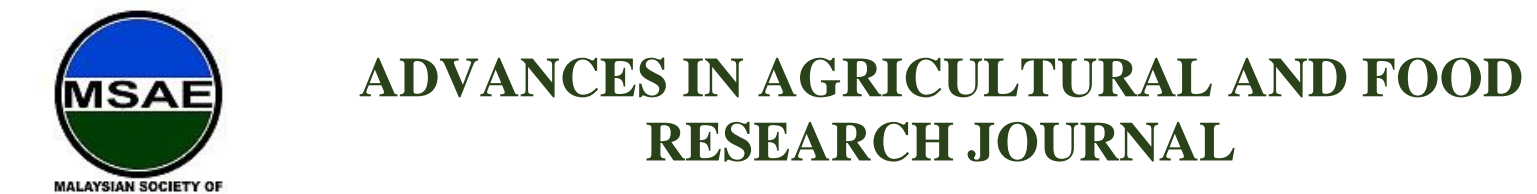

Editorial Note

\title{
1-year journey: An insight
}

Rosnah Shamsudin ${ }^{1}$

${ }^{1}$ Department of Process \& Food Engineering, Faculty of Engineering, Universiti Putra Malaysia, Serdang, 43400 Serdang Malaysia; rosnahs@upm.edu.my

Received: $29^{\text {th }}$ December 2020

Accepted: $30^{\text {th }}$ December 2020

Available Online: $31^{\text {st }}$ December 2020

Citation: Shamsudin R. 1-year journey: An insight. Adv Agri Food Res J 2020; 1(2): a0000163.

https://doi.org/10.36877/aafrj.a0000163

\section{Main Text}

On behalf of the Editorial Board Members of the Advances in Agricultural and Food Research Journal - (AAFRJ) (https://journals.hh-publisher.com/index.php/AAFRJ/index), I am glad to present the Volume 1, Issue 1 and Issue 2 of the journal for year 2020. The journal which was established in April 2020 has now published 2 issues; twice in a year. $\boldsymbol{A A F R \boldsymbol { J }}$ is a Gold open access journal and is also indexed in Google Scholar, Crossref and Malaysian Citation Centre (MyJurnal).

During the year of 2020, $\boldsymbol{A} \boldsymbol{A F R \boldsymbol { J }}$ received a total of 66 papers, out of which 33 papers will be published in Volume 2 Issue 1 for the year 2021. During 2020, 53 articles were accepted for publication after being evaluated in the peer review process. In the Volume 1 Issue 1, around 10 articles were published whereas for Volume 1 Issue 2, a total of 23 articles were published from authors around the world. A number of 105 research scientists and academics from all over the world reviewed the 33 articles published in Volume 1 Issue 1 and 2.

In another aspect, the average view per article is 37 and it is increasing as the year moves on. $\boldsymbol{A A F R} \boldsymbol{J}$ has reached this stage through the constant support of its respected Board Members, the readers and also the contributors, authors and reviewers alike.

$\boldsymbol{A A F R \boldsymbol { J }}$ is a refereed, scholarly journal publishing original research and review papers on any subject related to science and engineering in agricultural and food, particularly those of relevance to industry. These include, but are not limited to, applied agriculture, biology and environment, natural resources, food, and livestock farming with the intention of solving problems in complex living systems. In addition to science and engineering topics, 
we also welcome articles related to agriculture and food service extension, management and business both at local and international level.

I would like to take this opportunity to acknowledge the contributions of the Editorial Board Members, Senior Editors and the publisher during the final editing of all articles until they were published. I also would like to express my deepest appreciation to all our valuable authors, reviewers, readers and the Advisory Board Members for their interest, support and contributions to $\boldsymbol{A A F R J}$.

Celebrating the coming new year is exciting for everyone despite the ongoing COVID-19 pandemic. Year 2021 represents a new chapter. The calendar will change but the commitment would never waver. The hope is for a better year than the previous one. We, the $\boldsymbol{A A F R \boldsymbol { J }}$ editorial team, will continuously work hard to better service our authors and readers.

We hope that all could achieve their goals and let it be the best year of our life. Happy new year 2021!

Copyright $@ 2020$ by Shamsudin R. et al. and HH Publisher. This work is licensed under the Creative Commons 